\title{
Effects of a PPARG gene variant on obesity characteristics in Brazil
}

V.S. Mattevi ${ }^{1,2}$

V.M. Zembrzuski

and M.H. Hutz ${ }^{2}$
1Departamento de Ciências Fisiológicas, Fundação Faculdade Federal de Ciências Médicas de Porto Alegre, Porto Alegre, RS, Brasil

${ }^{2}$ Departamento de Genética, Universidade Federal do Rio Grande do Sul, Porto Alegre, RS, Brasil

\section{Correspondence}

M.H. Hutz

Departamento de Genética

Instituto de Biociências, UFRGS

Caixa Postal 15053

91501-970 Porto Alegre, RS

Brasil

Fax: +55-51-3308-6727

E-mail: mara.hutz@ufrgs.br

Research supported by CNPq,

PRONEX, and FAPERGS.

$\ldots \ldots \ldots \ldots \ldots \ldots \ldots$

Received September 20, 2006

Accepted March 28, 2007

\begin{abstract}
The contribution of genetic factors to the development of obesity has been widely recognized, but the identity of the genes involved has not yet been fully clarified. Variation in genes involved in adipocyte differentiation and energy metabolism is expected to have a role in the etiology of obesity. We assessed the potential association of a polymorphism in one candidate gene, peroxisome proliferator-activated receptor-gamma (PPARG $\gamma$ ), involved in these pathways and obesityrelated phenotypes in 335 Brazilians of European descent. All individuals included in the sample were adults. Pregnant women, as well as those individuals with secondary hyperlipidemia due to renal, liver or thyroid disease, and diabetes, were not invited to participate in the study; all other individuals were included. The gene variant PPARG Pro12Ala was studied by a PCR-based method and the association between this genetic polymorphism and obesity-related phenotypes was evaluated by analysis of covariance. Variant allele frequency was PPARG Ala12 $=0.09$ which is in the same range as described for European and European-derived populations. No statistically significant differences were observed for mean total cholesterol, LDL cholesterol, HDL cholesterol, or triglyceride levels among PPARG genotypes in either gender. In the male sample, an association between the PPARG Pro12Ala variant and body mass index was detected, with male carriers of the Ala variant presenting a higher mean body mass index than wild-type homozygotes (28.3 vs $\left.26.2 \mathrm{~kg} / \mathrm{m}^{2}, \mathrm{P}=0.037\right)$. No effect of this polymorphism was detected in women. This finding suggests that the PPARG gene has a gender-specific effect and contributes to the susceptibility to obesity in this population.
\end{abstract}

\section{Introduction}

Human obesity is a multifactorial disease with a significant heritable component. The energy imbalance that results in human obesity occurs as a result of genetic or acquired changes in eating behavior, physical activity, and efficiency of fuel storage and metabolism (1). Therefore, genes involved in
Key words

- Obesity

- PPARG gene

- Genetic susceptibility

- Multifactorial diseases energy metabolism and storage are good candidates as determinants of susceptibility to obesity.

Peroxisome proliferator-activated receptor-gamma (PPAR $\gamma$ ) is a transcription factor that plays a key role in activation of adipocyte differentiation and is an important modulator of gene expression in a number of specialized cell types, including adipocytes, 
where it acts by regulating the transcription of numerous target genes. Human PPAR $\gamma$ expression was first described in hematopoietic cells (2) and later also in spleen, liver, testis, skeletal muscle, and brain, in addition to fat (3). PPAR $\gamma$-signaling pathways affect both cellular and systemic lipid metabolism and have links to obesity, diabetes and cardiovascular disease (4). PPAR $\gamma$ exists as two isoforms, $\gamma 1$ and $\gamma 2$, generated by alternative promoters and differential splicing of at least three different transcripts from the $P P A R G$ gene on chromosome $3 \mathrm{p} 25(3,5)$. PPAR $\gamma 2$ is the most important isoform in adipose tissue, where it is almost exclusively expressed. A $\mathrm{C}>\mathrm{T}$ polymorphism located in the exon $\mathrm{B}$ of the PPARG gene, which codes the aminoterminal polypeptide that defines the PPAR $\gamma 2$ isoform, results in a Pro12Ala substitution. The Ala allele was shown to have reduced efficiency in transactivating responsive promoters (6) and a reduced ability to stimulate adipogenesis in response to thiazolidinedione activation (7). Nonetheless, results of studies on the association with this variant in man have been variable, both regarding the ability to detect an effect on obesity or glucose homeostasis and the direction of such effect (8).

Since the actual importance of the above gene variant to the development of obesity in human populations is a matter of controversy, the aim of the present study was to

Table 1. Anthropometric and lifestyle characteristics of 153 men and 182 women analyzed.

\begin{tabular}{lcc}
\hline & Men & Women \\
\hline Age (years) & $41.3 \pm 1.1$ & $38.7 \pm 1.2$ \\
Weight $(\mathrm{kg})$ & $78.3 \pm 1.1$ & $64.9 \pm 1.0^{*}$ \\
Height $(\mathrm{cm})$ & $171.8 \pm 0.6$ & $159.0 \pm 0.5^{*}$ \\
Body mass index $\left(\mathrm{kg} / \mathrm{m}^{2}\right)$ & $26.5 \pm 0.4$ & $25.7 \pm 0.4$ \\
Waist circumference $(\mathrm{cm})$ & $95.1 \pm 0.9$ & $86.4 \pm 0.9^{*}$ \\
Current smokers & $34.0 \%$ & $28.6 \%$ \\
Physically active & $47.1 \%$ & $28.6 \%$ \\
\hline
\end{tabular}

Data are reported as mean \pm SEM or as percent.

${ }^{\star} \mathrm{P}<0.0001$ compared to men (unpaired $t$-test). ${ }^{* \star} \mathrm{P}<0.0011$ compared to men (chisquare test). determine whether the Pro12Ala polymorphism of the PPARG gene contributes to variation in obesity-related phenotypes in a European-derived Southern Brazilian population, and to examine these results in the context of current findings related to the functions proposed for this protein.

\section{Subjects and Methods}

\section{Subjects}

The population studied, anthropometric measurements and biochemical analyses have been fully described elsewhere (9). Briefly, our sample comprised 335 individuals (153 men and 182 women) with body mass index (BMI, weight in $\mathrm{kg} /(\text { height in } \mathrm{m})^{2}$ ) ranging from 16.2 to $42.4 \mathrm{~kg} / \mathrm{m}^{2}$ (mean BMI: $26.1 \mathrm{~kg}$ / $\mathrm{m}^{2}$ ). All individuals were of European descent and resided in Porto Alegre city, capital of Brazil's southernmost state.

Data were collected regarding smoking habits, alcohol consumption, medication intake, regular engagement in leisure-time physical activity, and menopausal status. Weight, height and waist and hip circumferences were measured as previously described (9). The characteristics of the individuals investigated are shown in Table 1. To avoid the potential confounding effects of diabetes mellitus and its treatment on obesity-related phenotypes, individuals with a previous history of diabetes or fasting glucose levels over $7.0 \mathrm{mmol} / \mathrm{L}$ were excluded from the sample. All subjects signed an informed consent to participate in the study.

On the basis of the World Health Organization (10) criteria for BMI, $45.5 \%$ of the subjects were of normal weight, $36.6 \%$ were overweight and $17.9 \%$ were obese.

\section{Biochemical and DNA analyses}

Blood samples were collected from subjects after a 12-h fast. Total cholesterol, HDL cholesterol, triglycerides, and glucose 
levels were determined using standard enzymatic methods with a Selectra ${ }^{\circledR}$ autoanalyzer at the Clinical Analysis Laboratory of the Pharmacy School, Federal University of Rio Grande do Sul. LDL cholesterol was calculated by the method of Friedewald et al. (11). Genomic DNA was extracted from whole blood using a standard salting out procedure. Amplification by PCR was performed using published oligonucleotide sequences (12) to amplify the DNA region of interest containing the PPARG Pro12Ala polymorphism. Analysis of restriction fragment length polymorphism was employed to determine genotypes. After amplification, the PCR products were digested with the $B s t \mathrm{UI}$ restriction enzyme according to manufacturer recommendations. The digested products were subsequently separated by agarose gel electrophoresis and genotypes visualized using ethidium bromide staining.

\section{Statistical analysis}

Allele frequencies were estimated by gene counting. The agreement of genotype frequencies with Hardy-Weinberg expectations was tested using the goodness of fit chisquare test.

The association of the polymorphism with quantitative variables was tested by analysis of co-variance using general linear models. Since the other biological and environmental variables assessed (cigarette smoking, leisure-time physical activity, alcohol consumption, oral contraceptive use, hormone replacement therapy) made little or no contribution to the anthropometric variables (BMI and waist circumference), only age was included in these analyses as a co-variable. For lipid levels, the co-variables were age and BMI. Triglyceride levels were log transformed prior to analysis to remove skewness. Association analyses were performed separately for each gender. All analyses were performed using the SPSS 8.0.0 statistical package.

\section{Results}

The distribution of the Pro12Ala sequence variant among the individuals studied was 84.5\% Pro/Pro, $14.0 \%$ Pro/Ala, and $1.5 \%$ Ala/Ala. Genotype frequencies were as expected according to Hardy-Weinberg equilibrium. When compared with those observed in other studies, the frequency for the variant PPARG Ala-allele (0.09) was in the same range as described for European and European-derived populations (13).

The genotype and allele frequencies of the normal weight, overweight, and obese groups were compared by the chi-square test, but no statistically significant differences were observed (data not shown).

Association analyses of the PPARG Pro12Ala variant with BMI and waist circumference are presented in Table 2 . In the

\begin{tabular}{|c|c|c|c|c|c|c|c|}
\hline Genotype & $\mathrm{N}$ & $\begin{array}{c}\text { BMI } \\
\left(\mathrm{kg} / \mathrm{m}^{2}\right)\end{array}$ & $\begin{array}{l}\text { Waist circum- } \\
\text { ference }(\mathrm{cm})\end{array}$ & $\begin{array}{l}\text { Cholesterol } \\
\text { (mg/dL) }\end{array}$ & $\begin{array}{l}\text { LDL cholesterol } \\
\text { (mg/dL) }\end{array}$ & $\begin{array}{l}\text { HDL cholesterol } \\
\text { (mg/dL) }\end{array}$ & $\begin{array}{l}\text { Triglycerides } \\
(\mathrm{mg} / \mathrm{dL})^{\mathrm{a}}\end{array}$ \\
\hline \multicolumn{8}{|l|}{ Men } \\
\hline Pro/Pro & 130 & $26.2 \pm 0.4$ & $94.4 \pm 0.9$ & $200.9 \pm 3.5$ & $129.6 \pm 3.3$ & $40.5 \pm 0.9$ & $160.7 \pm 13.9$ \\
\hline Ala-carriers & 23 & $28.3 \pm 1.1^{*}$ & $98.8 \pm 2.7$ & $194.3 \pm 10.2$ & $117.1 \pm 6.7$ & $40.5 \pm 1.8$ & $187.9 \pm 34.1$ \\
\hline \multicolumn{8}{|l|}{ Women } \\
\hline Pro/Pro & 153 & $25.7 \pm 0.4$ & $86.6 \pm 1.0$ & $190.8 \pm 3.3$ & $118.1 \pm 2.8$ & $47.7 \pm 1.0$ & $123.6 \pm 7.6$ \\
\hline Ala-carriers & 29 & $25.5 \pm 0.8$ & $85.0 \pm 2.0$ & $188.0 \pm 6.9$ & $120.1 \pm 6.5$ & $46.0 \pm 2.0$ & $109.8 \pm 12.6$ \\
\hline
\end{tabular}

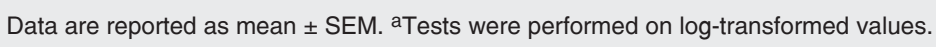
${ }^{*} \mathrm{P}=0.037$ compared to body mass index (BMI) of Pro/Pro subjects (ANCOVA). 
male sample, carriers of the Ala allele presented higher mean BMI than wild-type Pro/ Pro homozygotes $\left(28.3\right.$ vs $26.2 \mathrm{~kg} / \mathrm{m}^{2}, \mathrm{P}=$ 0.037), a feature that was not observed in women.

Since PPAR $\gamma$ plays a key role in adipogenesis and lipogenesis and treatment with PPAR $\gamma$-agonists alters plasma lipid profiles (14-16), the possible association between the Pro12Ala polymorphism and plasma lipid levels was also evaluated. However, no statistically significant differences were observed for mean total cholesterol, LDL cholesterol, HDL cholesterol, or triglyceride levels among PPARG genotypes in either gender (Table 2).

\section{Discussion}

Data regarding the association of the $P P A R G$ gene with human obesity have been conflicting. To clarify this issue, we investigated the Pro12Ala polymorphisms in a Brazilian population and searched for associations of this gene variant with obesity-related traits. Three previous studies investigated this polymorphism in the Brazilian population. Caramori et al. (17) concluded that the presence of the Ala allele may confer protection from diabetic nephropathy in patients with type 2 diabetes, whereas Tavares et al. (18) suggested that subjects with diabetes carrying the Ala12 allele could be more sensitive to insulin than those homozygous for Pro12. A third study (19) with 85 Parkateje Indians from the Brazilian Amazon region described an association between the Pro 12Ala variant and features of metabolic syndrome. Almost all individuals in their sample were classified as having normal glucose tolerance. The present study focused only on non-diabetic individuals to avoid these potential confounding effects of diabetes on BMI.

The primary effect of PPARG seems to be on body weight; at least 10 studies (13) have shown an association between the Ala allele and higher BMI or obesity, although many negative results have also been reported (13), as well as six studies associating the Ala allele and a decrease in BMI (13). Despite the fact that a number of studies may represent type I or type II errors due, for instance, to small sample size or population stratification, there are a growing number of better designed studies with at least moderate sample sizes, showing that statistical errors may not be sufficient to explain discrepancies among association studies. Furthermore, three longitudinal studies consistently suggested greater weight gain in carriers of the Ala allele (20-22). A meta-analysis concerning the effect of the Pro12Ala variant on BMI concluded that Ala12 allele carriers have a significantly higher BMI than noncarriers, but this effect is restricted to individuals with a BMI of $27 \mathrm{~kg} / \mathrm{m}^{2}$ or higher (23). An explanation for these inconsistencies was provided by a recently published meta-analysis that showed that the effect of the Pro12Ala polymorphism was restricted to Caucasian populations and obese subjects. In that analysis the Ala12 carriers presented significantly increased BMI (24).

In the present study, the effect of the Pro12Ala variant was restricted to males. Male-restricted associations of PPARG with obesity-related phenotypes have also been found in other studies, together with femalespecific effects (13). PPAR $\gamma$ has been shown to inhibit the expression of the aromatase gene, a key enzyme in estrogen biosynthesis (25). Conversely, a recent study demonstrated that estrogens can induce expression of the small heterodimer partner, a nuclear receptor that can modulate the activity of several transcription factors, including PPAR $\alpha$ and PPAR $\gamma$ (26). Hence, hormonal factors may potentially modulate the action of PPARG variants and underlie these gender-specific associations. Notice, however, that not only differences in hormones and fat-distribution patterns among genders, but also sex-specific lifestyle components such as differences 
in smoking habits, physical activity, diet or alcohol consumption may act as modifiers of the effect of gene variants in determining the risk of obesity.

Therefore, although in vitro assays suggest that the Pro12Ala variant would reduce PPAR $\gamma$ ability to stimulate adipogenesis, in vivo studies indicate a more complex scenario, with multiple interactions among biological and environmental factors in the determination of its biological role. For instance, Cardona et al. (27) recently demonstrated that patients with the metabolic syndrome who are Ala12 carriers are more prone to postprandial hypertriglyceridemia. Furthermore, these investigators found a significant interaction between the Pro12Ala and apolipoprotein E genotypes in the determination of this phenotype. The modulation of PPAR $\gamma$ activity by several co-factors (28) makes this scenario even more complex; it seems that the effect of PPAR $\gamma$ is highly context dependent, a feature that must be further explored in other studies. On the other hand, it is important to keep in mind that the Pro12Ala variant could be in linkage disequilibrium with an unknown variant elsewhere in the gene, which could explain the discrepancies among results of association studies in different populations.

\section{Acknowledgments}

Thanks are due to Ana Lúcia S. Antunes and Maria Perpetua de Oliveira Pinto from the Clinical Analysis Laboratory of the Pharmacy College, Federal University of Rio Grande do Sul, and to Fabiana M. de Andrade, Marilu Fiegenbaum, Silvana de Almeida and Marcel Arsand for help with sample collection.

\section{References}

1. Palou A, Serra F, Bonet ML, Pico C. Obesity: molecular bases of a multifactorial problem. Eur J Nutr 2000; 39: 127-144.

2. Greene ME, Blumberg B, McBride OW, Yi HF, Kronquist K, Kwan K, et al. Isolation of the human peroxisome proliferator activated receptor gamma cDNA: expression in hematopoietic cells and chromosomal mapping. Gene Expr 1995; 4: 281-299.

3. Elbrecht A, Chen Y, Cullinan CA, Hayes N, Leibowitz M, Moller DE, et al. Molecular cloning, expression and characterization of human peroxisome proliferator activated receptors gamma 1 and gamma 2. Biochem Biophys Res Commun 1996; 224: 431-437.

4. Walczak R, Tontonoz P. PPARadigms and PPARadoxes: expanding roles for PPARgamma in the control of lipid metabolism. J Lipid Res 2002; 43: 177-186.

5. Farmer S. Transcriptional control of adipogenesis: interplay between C/EBPs and PPAR $\gamma$ in regulating adipocyte gene expression. In: Medeiros-Neto G (Editor), Progress in obesity research. Paris: John Libbey Eurotext; 2003. p 15-18.

6. Deeb SS, Fajas L, Nemoto M, Pihlajamaki J, Mykkanen L, Kuusisto $\mathrm{J}$, et al. A Pro12Ala substitution in PPARgamma2 associated with decreased receptor activity, lower body mass index and improved insulin sensitivity. Nat Genet 1998; 20: 284-287.

7. Masugi J, Tamori Y, Mori H, Koike T, Kasuga M. Inhibitory effect of a proline-to-alanine substitution at codon 12 of peroxisome proliferator-activated receptor-gamma 2 on thiazolidinedione-induced adipogenesis. Biochem Biophys Res Commun 2000; 268: 178-182.

8. Hasstedt SJ, Ren QF, Teng K, Elbein SC. Effect of the peroxisome proliferator-activated receptor-gamma 2 pro(12)ala variant on obesity, glucose homeostasis, and blood pressure in members of famil- ial type 2 diabetic kindreds. J Clin Endocrinol Metab 2001; 86: 536541.

9. Mattevi VS, Zembrzuski VM, Hutz MH. Association analysis of genes involved in the leptin-signaling pathway with obesity in Brazil. Int $J$ Obes Relat Metab Disord 2002; 26: 1179-1185.

10. WHO (World Health Organization). Obesity: preventing and managing the global epidemic. Report of a WHO consultation on obesity. 1997 3-5 June; Geneva. Geneva: World Health Organization; 1998.

11. Friedewald WT, Levy RI, Fredrickson DS. Estimation of the concentration of low-density lipoprotein cholesterol in plasma, without use of the preparative ultracentrifuge. Clin Chem 1972; 18: 499-502.

12. Yen CJ, Beamer BA, Negri C, Silver K, Brown KA, Yarnall DP, et al. Molecular scanning of the human peroxisome proliferator activated receptor gamma (hPPAR gamma) gene in diabetic Caucasians: identification of a Pro12Ala PPAR gamma 2 missense mutation. Biochem Biophys Res Commun 1997; 241: 270-274.

13. Meirhaeghe A, Amouyel P. Impact of genetic variation of PPAR gamma in humans. Mol Genet Metab 2004; 83: 93-102.

14. Ghazzi MN, Perez JE, Antonucci TK, Driscoll JH, Huang SM, Faja BW, et al. Cardiac and glycemic benefits of troglitazone treatment in NIDDM. The Troglitazone Study Group. Diabetes 1997; 46: 433439.

15. Nozue T, Michishita I, Minagawa F, Genda A. Troglitazone directly increases HDL cholesterol levels. Diabetes Care 1999; 22: 355-356.

16. Akiyama TE, Sakai S, Lambert G, Nicol CJ, Matsusue K, Pimprale $S$, et al. Conditional disruption of the peroxisome proliferator-activated receptor gamma gene in mice results in lowered expression of $A B C A 1, A B C G 1$, and apoE in macrophages and reduced choles- 
terol efflux. Mol Cell Biol 2002; 22: 2607-2619.

17. Caramori ML, Canani LH, Costa LA, Gross JL. The human peroxisome proliferator-activated receptor gamma2 (PPARgamma2) Pro12Ala polymorphism is associated with decreased risk of diabetic nephropathy in patients with type 2 diabetes. Diabetes 2003; 52: 3010-3013.

18. Tavares V, Hirata RD, Rodrigues AC, Monte O, Salles JE, Scalissi $\mathrm{N}$, et al. Association between Pro12Ala polymorphism of the PPARgamma2 gene and insulin sensitivity in Brazilian patients with type-2 diabetes mellitus. Diabetes Obes Metab 2005; 7: 605-611.

19. Vieira-Filho JP, Reis AF, Kasamatsu TS, Tavares EF, Franco LJ, Matioli SR, et al. Influence of the polymorphisms Tpr64Arg in the beta 3-adrenergic receptor gene and Pro12Ala in the PPAR gamma 2 gene on metabolic syndrome-related phenotypes in an indigenous population of the Brazilian Amazon. Diabetes Care 2004; 27: 621622.

20. Douglas JA, Erdos MR, Watanabe RM, Braun A, Johnston CL, Oeth $P$, et al. The peroxisome proliferator-activated receptor-gamma2 Pro12A1a variant: association with type 2 diabetes and trait differences. Diabetes 2001; 50: 886-890.

21. Lindi V, Sivenius K, Niskanen L, Laakso M, Uusitupa MI. Effect of the Pro12Ala polymorphism of the PPAR-gamma2 gene on longterm weight change in Finnish non-diabetic subjects. Diabetologia 2001; 44: 925-926.

22. Nicklas BJ, van Rossum EF, Berman DM, Ryan AS, Dennis KE,
Shuldiner AR. Genetic variation in the peroxisome proliferator-activated receptor-gamma2 gene (Pro12Ala) affects metabolic responses to weight loss and subsequent weight regain. Diabetes 2001; 50: 2172-2176.

23. Masud S, Ye S. Effect of the peroxisome proliferator activated receptor-gamma gene Pro12Ala variant on body mass index: a meta-analysis. J Med Genet 2003; 40: 773-780.

24. Tonjes A, Scholz M, Loeffler M, Stumvoll M. Association of Pro12Ala polymorphism in peroxisome proliferator-activated receptor gamma with pre-diabetic phenotypes: meta-analysis of 57 studies on nondiabetic individuals. Diabetes Care 2006; 29: 2489-2497.

25. Memisoglu A, Hankinson SE, Manson JE, Colditz GA, Hunter DJ. Lack of association of the codon 12 polymorphism of the peroxisome proliferator-activated receptor gamma gene with breast cancer and body mass. Pharmacogenetics 2002; 12: 597-603.

26. Lai K, Harnish DC, Evans MJ. Estrogen receptor alpha regulates expression of the orphan receptor small heterodimer partner. J Biol Chem 2003; 278: 36418-36429.

27. Cardona F, Morcillo S, Gonzalo-Marin M, Garrido-Sanchez L, Macias-Gonzalez M, Tinahones FJ. Pro12Ala sequence variant of the PPARG gene is associated with postprandial hypertriglyceridemia in non-E3/E3 patients with the metabolic syndrome. Clin Chem 2006; 52: 1920-1925.

28. Fajas L. Adipogenesis: a cross-talk between cell proliferation and cell differentiation. Ann Med 2003; 35: 79-85. 